\title{
Guillaume Dye, Fabien Nobilio (dir.), Figures bibliques en islam
}

Bruxelles, EME, coll. « Religion et Altérité », 2011, 215 p.

\section{Bernard Heyberger}

\section{(2) OpenEdition}

\section{Journals}

\section{Édition électronique}

URL : http://journals.openedition.org/assr/26390

DOI : $10.4000 /$ assr. 26390

ISSN : $1777-5825$

Éditeur

Éditions de l'EHESS

Édition imprimée

Date de publication : 31 décembre 2014

Pagination : 177

ISBN : 978-2-7132-2467-6

ISSN : 0335-5985

\section{Référence électronique}

Bernard Heyberger, "Guillaume Dye, Fabien Nobilio (dir.), Figures bibliques en islam », Archives de sciences sociales des religions [En ligne], 168 | 2014, mis en ligne le 14 avril 2015, consulté le 22 septembre 2020. URL : http://journals.openedition.org/assr/26390 ; DOI : https://doi.org/10.4000/ assr. 26390

Ce document a été généré automatiquement le 22 septembre 2020.

(c) Archives de sciences sociales des religions 


\section{Guillaume Dye, Fabien Nobilio (dir.), Figures bibliques en islam}

Bruxelles, EME, coll. « Religion et Altérité », 2011, 215 p.

Bernard Heyberger

\section{RÉFÉRENCE}

Guillaume Dye, Fabien Nobilio (dir.), Figures bibliques en islam, Bruxelles, EME, coll. « Religion et Altérité », 2011, 215 p. 
1 Dans l'abondante production coranologique, voici un (rare) ouvrage en français. Il donne d'abondantes références bibliographiques à jour dans ce domaine, avec parfois des remarques critiques. Les articles qui le composent offrent d'autre part une illustration des approches et des débats actuels entre spécialistes du champ. Le lecteur peut donc s'en saisir comme d'une porte d'entrée dans la discipline coranologique.

Le livre s'inscrit dans le travail actuel sur l'intertextualité, qui postule l'hypothèse d'un lien fort entre le christianisme et l'islam dans leurs Écritures respectives, ou plutôt entre les traditions vivantes $d u$ texte biblique interprété par les fidèles, et le Coran. Il part de la méthode d'étude

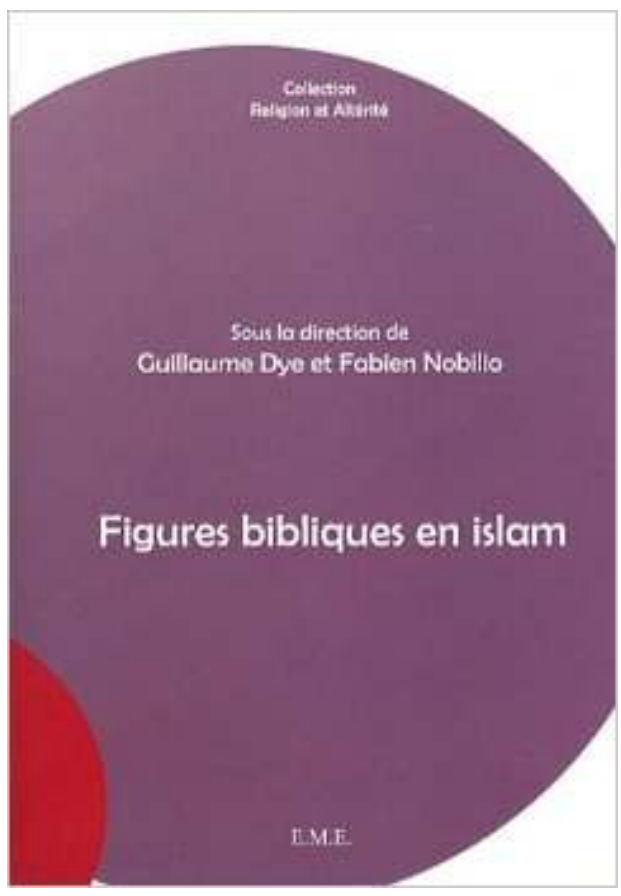
intertextuelle expérimentée pour la Bible, pour l'appliquer au Coran et aux écritures de la tradition islamique. Il aborde le Coran comme un texte appartenant à l'Antiquité tardive et devant donc être contextualisé avec les autres productions écrites de la même époque et de la même aire culturelle. Ce faisant, il récuse la perspective fréquente (et islamique) d'une étude du Coran fondée exclusivement sur la tradition musulmane plus tardive, qu'il considère comme anachronique. Dans leur introduction, les deux éditeurs scientifiques se livrent à un véritable manifeste pour un dialogue entre biblistes et islamologues, "pour une réintégration des études islamiques (et a fortiori des études coraniques) dans les études bibliques et sémitiques ou, plus précisément, dans l'histoire religieuse, linguistique, littéraire et culturelle du ProcheOrient de l'Antiquité tardive. "

3 L'intention de s'inscrire dans le dialogue islamo-chrétien actuel affleure lorsque, dans leur introduction, les auteurs soupèsent les «figures » bibliques dans le Coran. Ces figures «communes » ne sont pas forcément "partagées », dans la mesure où, même sans intention polémique, elles s'inscrivent dans le Coran dans une économie de la prophétie proprement islamique, qui se réapproprie les figures d'Abraham ou de Jésus dans un sens clivant par rapport à l'interprétation chrétienne. C'est notamment le cas de la figure de Jésus : " on doit bel et bien parler de christologies concurrentes ». Le texte conclusif de Jacques Chopineau (" "notre père Abraham" et les prophètes bibliques ») n'évite pas une approche chrétienne du "dialogue interreligieux", lorsque, par exemple, il affirme: «Il ne faudrait pas que l'actualité tragique en Palestine cache la longue histoire commune et les similitudes entre le judaïsme et l'islam ».

4 L'article de Michel Tardieu, «Les Sept Dormants : magie, facétie, temps infini », part de l'affirmation d'une " mutation du conte oral régional en hagiographie universelle » et de «multiples combinaisons d'éléments culturels et religieux qui jouent dans cette transformation", ce qui place l'étude de la légende des Sept Dormants "dans une situation difficilement maîtrisable d'intertextualité ». Il en fait néanmoins la tentative, en se livrant à une critique historiographique avant de formuler sa propre 
interprétation, prenant en particulier ses distances avec l'interprétation militante des Sept Dormants par Louis Massignon. Contrairement à ce dernier, il situe bien l'origine de la légende dans le contexte éphésien, caractérisé par «le cultuel magique et le narratif facétieux ». Cette origine éphésienne et antique est aussi orale, la version savante n'en ayant été diffusée que plus tardivement. Ce raisonnement arrive à la conclusion que la recension coranique de la légende (sourate 18), mettant en avant la symbolique astrale de l'espace des Sept Dormants, est plus proche de l'environnement païen dans laquelle le conte de tradition orale a pris corps, que la version chrétienne, fruit d'un recyclage des traditions locales en fonction des progrès de la christianisation et des besoins de la théologie officielle.

Daniel De Smet, «Marie, Marie Madeleine, Zacharie, Jean-Baptiste et Simon-Pierre : auxiliaires de Jésus selon la prophétologie shi'ite ismaélienne », part de la spécificité de la notion de prophétie chez les ismaéliens pour expliquer leur usage des figures évangéliques. En effet, leur théologie se caractérise par une théorie de l'imamat qui relie chaque imam à un prophète, combinée à une conception cyclique de l'histoire religieuse de l'humanité construite autour du nombre sept. Ainsi, sept cycles prophétiques sont censés se succéder dans l'histoire. D'où le recours aux figures bibliques pour les cycles antérieurs à la prophétie de Muhammad. La figure de Marie est interprétée de même dans cette conception cyclique, occupant la même place et jouant le même rôle dans l'histoire du Salut que Khadîja. Marie-Madeleine, qui n'apparait pas dans le Coran, trouve chez un auteur ismaélien une place comparable à celle qu'elle occupe dans des écrits gnostiques et des évangiles apocryphes : elle est la dépositaire du sens secret et caché des Évangiles, et donc "l'épouse spirituelle » de Jésus. Les sources chrétiennes de cette doctrine ismaélienne de la prophétie et de l'imamat restent encore à déterminer. 